\title{
Dormência vegetativa da nogueira-pecã - Uma revisão
}

\author{
Claudia Farela Ribeiro Crosa', Rudinei De Marco ${ }^{2}$, Rafaela Schmidt de Souza ${ }^{3}$ e Carlos Roberto Martins ${ }^{4}$
}

Resumo - A nogueira-pecã é uma frutífera que necessita de baixas temperaturas no período hibernal para que possa induzir e superar a dormência, restabelecendo assim um novo ciclo de desenvolvimento produtivo. Através desta revisão, o produtor poderá ter informações confiáveis da exigência climática da cultura, a fim de respaldar sua tomada de decisão sobre práticas de gestão que reduzam os danos causados por esses fenômenos e sirvam para otimizar o sistema de produção, melhorando seus lucros. Em vista disso, torna-se propício adaptar informações sobre a cultura com foco na exigência em frio hibernal necessária para a superação da dormência dos cultivares de nogueira-pecã. Pôde-se constatar a divergência entre os autores em relação à necessidade de frio para a nogueira-pecã, bem como a necessidade de mais trabalhos no que se refere aos produtos utilizados para induzir a brotação na nogueira-pecã.

Termos para indexação: Pecan; Carya illinoinensis; Dormência; Horas de frio; Requerimento de frio.

\section{Vegetative dormancy of pecan - A review}

\begin{abstract}
Pecan is a fruit tree that needs low temperatures in the winter, so that it can induce and overcome dormancy, reestablishing a new cycle of productive development. Through this review, the producer will be able to have reliable information on the climatic requirement of the crop, in order to support his decision making on management practices that reduce the damage caused by these phenomena and serve to optimize the production system, improving his profits. In view of this, it becomes propitious to adapt information about the crop with a focus on the requirement for winter cold necessary to overcome the dormancy of pecan cultivars. It was possible to verify the divergence between the authors in relation to the need for cold for pecan and the need for more work about the products used to induce sprouting in pecan.
\end{abstract}

Index terms: Pecan; Carya illinoinensis; Dormancy; Cold hours; Cold requirement.

\section{Introdução}

\subsection{Classificação botânica, origem e características da planta}

A nogueira-pecã Carya illinoinensis (Wangenh) K. Koch pertence à família botânica Juglandaceae, conhecida como a família das nozes (MCWILLIAMS, 2013). Ocorre de forma natural em extensas áreas nas regiões temperadas do Hemisfério Norte, mais precisamente no Sul dos Estados Unidos até o Norte do México (WELLS, 2017a).

\subsection{Importância socioeconômica da nogueira-pecã}

O plantio comercial da cultura vem crescendo anualmente em todos os continentes, porém os países de origem continuam sendo os maiores produtores mundiais do fruto (BILHARVA et al.,
2018). O México atualmente alcançou a primeira posição no que diz respeito à produção mundial de nogueira-pecã, ou seja, é o principal produtor da cultura (145,5 mil toneladas). Os Estados Unidos ocupam a segunda posição (126,5 mil toneladas), sendo também um dos principais consumidores. As estimativas atuais indicam que o México está produzindo mais de $50 \%$ do total global de nozes (COMENUEZ, 2020).

Na América do Sul, o Peru conta com cerca de 3.000ha, e o Uruguai com uma área de aproximadamente 600ha. A Argentina possui cerca de 6.000 ha, sendo 1.500 ha em plena produção. Já no Brasil, a área destinada ao cultivo da nogueira-pecã ultrapassa os 8.000 ha (MARTINS et al., 2018). No Brasil a nogueira-pecã é cultivada da Região Sul do país até o estado de Minas Gerais. Os plantios comerciais, principalmente os com maiores extensões de área, encon- tram-se nas regiões do Vale do Taquari, Rio Pardo e central do estado do Rio Grande do Sul (POLETTO et al., 2016).

\section{Dormência}

A dormência é o mecanismo que as árvores frutíferas caducifólias usam para proteger o tecido sensível de condições desfavoráveis durante o inverno. Fatores como condições ambientais desfavoráveis, temperaturas ou fotoperíodo geralmente induzem inatividade do meristema (CASALES et al., 2018). O desenvolvimento de diferentes estratégias adaptativas permitiu a sobrevivência das frutíferas de clima temperado em suas regiões de origem, que são caracterizadas pelas baixas temperaturas durante o período de outono e inverno (HAWERROTH et al., 2010a).

Lang et al. (1987) verificaram que a dormência é um processo de desen-

Recebido em 3/3/2021. Aceito para publicação em 30/4/2021.

http//:dx.doi.org/10.52945/rac.v34i2.1139

${ }^{1}$ Engenheira-agrônoma, Mestranda no Programa de Pós-Graduação em Agronomia - Fruticultura de Clima Temperado da Universidade Federal de Pelotas, e-mail: crosa_claudia@yahoo.com.br

${ }^{2}$ Engenheiro Florestal, Doutorando no Programa de Pós-Graduação em Agronomia - Fruticultura de Clima Temperado da Universidade Federal de Pelotas; e-mail: rudineidemarco@hotmail.com

${ }^{3}$ Engenheira-agrônoma, Doutoranda no Programa de Pós-Graduação em Agronomia - Fruticultura de Clima Temperado da Universidade Federal de Pelotas; e-mail: souzarafaela15@yahoo.com.br

${ }^{4}$ Engenheiro-agrônomo, Dr., Pesquisador Embrapa Clima Temperado; e-mail: carlos.r.martins@embrapa.br 
volvimento que envolve a suspensão provisória do crescimento de alguma estrutura vegetal contendo um meristema, caracterizado pelo controle do crescimento e pela obtenção da resistência ao frio. Essa é a definição mais aceita universalmente. Não é um mecanismo que é adquirido rapidamente pelas plantas, mas sim um processo de desenvolvimento progressivo que tem início durante o outono, aumentando sua intensidade até alcançar a dormência profunda ou endodormência (RUIZ et al., 2007). Este fenômeno da dormência foi divido por Lang et al. (1987) em três diferentes fases: paradormência, endodormência e ecodormência.

A paradormência é a inibição correlativa, quando um determinado órgão impede o crescimento do outro e é possível a retomada imediata do crescimento com a eliminação do inibidor. A dominância apical ocorre quando o desenvolvimento das gemas axilares, que ficam situadas abaixo das gemas terminais, não é visualizado. É um exemplo respectivo de paradormência, visto que as gemas axilares permanecem em situação de dormência mesmo estando em condições favoráveis, somente retomando o crescimento se houver interrupção do fator inibição (LANG et al., 1987).

A endodormência é a paralisação do desenvolvimento da gema como uma forma de sobrevivência em condições ambientais desfavoráveis ao seu crescimento, como a temperatura e o déficit hídrico. A origem da inibição situa-se no próprio meristema e o crescimento não ocorre de forma normal, mesmo que as condições ambientais sejam favoráveis e as inibições correlativas forem suprimidas. Quanto mais profunda essa etapa, maior será o número de horas de frio para superá-la. A quantidade de frio ocorrida desde a indução até a superação da endodormência é denominada requerimento em frio, sendo determinada para cada espécie e até mesmo cultivar (LANG et al., 1987).

Ainda em relação à endodormência, Faust et al. (1997) mencionam que ela pode ser dividida em duas fases: dormência profunda (d-endodormência) e s-endodormência (dormência superficial). A primeira é caracterizada pela incapacidade de induzir gemas ao crescimento, exceto em condições ambien- tais favoráveis. Já na segunda, com os tratamentos adequados, a dormência pode ser rompida.

A ecodormência caracteriza-se pela não brotação das gemas e é procedente de fatores extrínsecos à planta e limitantes do desenvolvimento, como, por exemplo, as baixas temperaturas (LANG et al., 1987; HAWERROTH et al., 2010a). No caso particular das frutíferas de clima temperado, é a última fase de repouso de inverno. Após a superação da endodormência, as gemas continuam em repouso até que ocorra o acúmulo de calor suficiente para poder ocorrer a retomada do crescimento (HAWERROTH et al., 2010a).

\section{Dormência na nogueira- pecã}

A nogueira-pecã é uma planta frutífera que possui fase vegetativa, reprodutiva e senescência, devendo necessariamente passar por um período que é denominado de dormência. No Brasil esse período se inicia em meados de maio e se estende até o mês de setembro (FRONZA et al., 2018).

Ao se desenvolver em seu habitat natural, a planta raramente é danificada pelo frio, pois em sua evolução desenvolveu mecanismos com adaptações fisiológicas que permitem que ela permaneça dormente e sobreviva, mesmo em invernos muito rigorosos (GRAGEDA et al., 2016). Segundo esses mesmos autores, quando a espécie é cultivada em regiões com deficiência de frio, onde ele não é fornecido adequadamente, isso acarretará brotação e floração irregulares e, por longo período, foliação atrofiada, com pouca ramificação e, por consequência, os rendimentos tendem a ser bem abaixo do potencial.

As temperaturas extremamente baixas não contribuem para a superação da dormência da nogueira-pecã. Existem temperaturas ótimas para o acúmulo de frio durante o inverno. O requisito de frio para a cultura pode variar de acordo com as condições do outono (KUDEN et al., 2013). Se as árvores forem expostas a temperaturas de outono mais frias $\left(<1^{\circ} \mathrm{C}\right)$, o número de horas de resfriamento necessárias para a saída da dormência e a abertura da gema aumenta (MELKE, 2015).
A intensidade e a duração do repouso de uma gema são dadas individualmente. A necessidade de uma gema ou órgão de ser exposto a baixas temperaturas por um período mínimo para terminar seu estado de repouso é chamada de requerimento ou necessidade de frio. É importante reiterar que o principal fator para terminar o repouso são as baixas temperaturas, pois sem estas não haveria brotação adequada e uniforme (GRAGEDA et al., 2016).

Na região de Adana, na Turquia, Kuden et al. (2013) relatam que, embora se saiba que a nogueira-pecã é de baixo requerimento em frio (cerca de 400 horas), as necessidades de frio de todos os cultivares comerciais ainda não são conhecidas.

No Brasil, existem alguns relatos sobre a necessidade de horas frio da nogueira-pecã. Raseira (1990) descreve que a nogueira-pecã satisfaz-se com 400 horas de frio abaixo de $7,2^{\circ} \mathrm{C}$ para a superação da dormência e esses valores variam de acordo com o cultivar, os tipos de gema e a parte da planta. Fronza et al. (2018) mencionam que no Rio Grande do Sul tem-se observado bom desempenho produtivo dos cultivares utilizados em regiões com acúmulo em torno de 100 a 200 horas. Porém, são dados gerais e baseados em parâmetros de observações de desenvolvimento e produção da planta, não levando em consideração aspectos intrínsecos da fisiologia da dormência e nem distinguindo diferentes cultivares.

O número de horas de frio necessário para a abertura das gemas da nogueira-pecã varia de acordo com o cultivar. Alguns estudos (em plantas) expuseram que 300 a 500 horas de frio foram necessárias para 'Desirable', 'Mahan', 'Success' e 'Schley', enquanto 'Stuart' requeria de 600 a mais de 1.000 horas. Entretanto, a abertura da gema poderá ocorrer com menos de 100 horas de frio, mas isso pode levar à brotação desigual das gemas e subsequentes problemas de polinização (WELLS, 2017a).

Existem autores que em pesquisas anteriores afirmavam a necessidade de frio e em ensaios mais recentes concluíram o contrário. Lemus (2004) e Grageda (2020) afirmam que a nogueira-pecã não requer frio no inverno. De acordo com eles, as gemas floríferas e vegetativas respondem a temperaturas superio- $\downarrow$ 
res aos $10^{\circ} \mathrm{C}$, que ocorrem no início da primavera, independentemente do acúmulo de frio durante o período invernal.

Melke (2015) assegura que a gema da nogueira-pecã pode vir a brotar com menos de 100 horas de frio, mas isso pode levar a uma abertura desigual e problemas subsequentes com polinização. A falta de horas de frio não irá impedir o desenvolvimento das nogueiras, mas pode vir a afetar a brotação rápida e completa (ROVANI \& WOLLMANN, 2018). Já Wells (2017b) afirma que a nogueira-pecã não possui um período crítico de necessidade de frio e que, ao invés disso, possui uma combinação de frio e aquecimento. Lemus (2004) e Grageda et al. (2020) propuseram que a brotação fosse regulada mais por um requisito de calor do que por um requerimento de frio.

Ao que tudo indica as unidades de calor na primavera, em vez de unidades de frio no inverno, são as mais limitantes para o crescimento da nogueira-pecã. Sob condições de alto frio, um calor mínimo é necessário para a abertura das gemas na primavera, permitindo que elas comecem a crescer o mais rápido possível. Isso aumenta a probabilidade de que o ciclo de frutificação seja concluído em um período relativamente curto (WELLS, 2017a). De modo geral, temperaturas mais elevadas no final do mês de agosto e início de setembro (período que compreende o início de um novo ciclo de desenvolvimento) podem proporcionar melhor brotação e desenvolvimento da cultura.

A brotação pode ocorrer com pouco frio, mas existe uma variação significativa quando o número de horas de frio (HF) é inferior a 100 horas. À medida que mais HF se acumulam no inverno, menor é o calor que será necessário na primavera para estimular uma brotação das flores de maneira mais uniforme. Essa adaptação permite que as plantas se desenvolvam sob uma ampla gama de condições climáticas (WELLS, 2017b).

Grande parte dos autores que estuda ou trabalha com a nogueira-pecã (RASEIRA, 1990; LEMUS, 2004; GRAGEDA et al., 2016) salienta que a cultura necessita de um acúmulo de mais de $400 \mathrm{HF}$ para que possa superar a dormência. Contudo, outros autores afirmam que a mesma pode ser cultivada em regiões com o acúmulo entre 250 e
550 HF (RASEIRA, 1990; GRAGEDA et al., 2016) e ainda, com um acúmulo de 50 a 100 HF (OJEDA-BARRIOS et al., 2009; WELLS, 2017a). Nesse contexto, a literatura é muito ampla, com valores estimados variando de 50 a mais de $550 \mathrm{HF}$.

\section{Métodos de avaliação da dormência}

Estudos em condições controladas são necessários para determinar de uma forma mais precisa o requerimento de frio das frutíferas de clima temperado. Sendo assim, diversos métodos biológicos são utilizados com essa finalidade.

Encontram-se muitas variações dos métodos biológicos, podendo-se utilizar plantas inteiras ou apenas partes destas, sendo a diferença entre os métodos determinada pelos objetivos específicos de cada pesquisa. Este método é utilizado para verificar quando o período de endodormência foi superado, visto que a única inibição para esta gema brotar vem da própria gema, pois as demais são eliminadas, não tendo inibição por outro órgão da planta (HAWERROTH et al., 2010a).

O método biológico mais utilizado é o uso de ramos destacados, no qual se utilizam ramos com aproximadamente $15 \mathrm{~cm}$. Após a exposição às condições experimentais, submete-se o material vegetal a condições ideais (fotoperíodo e temperatura) ao desenvolvimento das gemas, quantificando a brotação (HAWERROTH et al., 2010a). De acordo com os autores, ainda existe o teste de estacas de nós isolados, que utiliza porções dos ramos contendo apenas um nó com gemas. Elimina-se, assim, grande parte das inibições correlativas submetendoos a condições adequadas de crescimento e obtendo-se a profundidade de dormência das gemas, expressa pelo tempo médio para brotação.

Os métodos que utilizam ramos destacados ou nós isolados possibilitam trabalhar com grande número de gemas em espaços reduzidos, permitindo maior amplitude de resposta a diferentes condições térmicas. Entretanto, a longevidade do material pode ser comprometida, por desidratação dos tecidos vegetais, devendo-se ter maior cuidado com a umidade relativa (HAWERROTH et al., 2010a). Ainda assim, mesmo com algumas desvantagens, é o único teste capaz de avaliar a profundidade de dormência intrínseca à gema, em razão de eliminar grande parte das inibições correlativas que atuam sobre ela, embora não consiga eliminar a inibição existente no eixo da gema que a une ao ramo.

\section{Métodos de cálculo de acúmulo de frio}

A modelagem de previsão do início do ciclo vegetativo anual, em frutíferas caducifólias, por meio da quantificação de horas de frio, é de extrema importância para a tomada de decisão quanto à necessidade ou não de aplicação de produtos químicos para a superação da dormência.

Para mensurar a quantidade de frio necessária a fim de superar a dormência das gemas o modelo mais utilizado é a soma diária das horas, HF (de horas de frio), com temperaturas iguais ou inferiores a $7,2^{\circ} \mathrm{C}$, durante o período de maio a setembro (CARDOSO et al., 2015; SANTOS et al., 2017). Contudo, este modelo não tem sido muito satisfatório, uma vez que o número de horas requeridas para a superação da dormência não é o mesmo em anos com regimes diferentes de temperatura, além de não considerar qualquer acúmulo de frio para temperaturas acima de $7,2^{\circ} \mathrm{C}$. Para isso, existem outros modelos que têm sido empregados com essa finalidade que levam em consideração Unidades de frio, como Utah, Utah Modificado e Carolina do Norte, entre outros (RICHARDSON et al., 1974; SHALTOUT \& UNRATH, 1983 ).

\section{Produtos utilizados para superação da dormência}

Com o intuito de poder minimizar algumas anomalias (florescimento irregular, baixa taxa de brotação e florescimento), usam-se produtos químicos para a indução da brotação. Contudo, sua eficiência está relacionada à época de aplicação, e isso significa que as gemas necessitam estar em processo de crescimento, ou seja, com a endodormência superada (LEITE, 2020).

Em meio às diversas opções que se encontram disponíveis no mercado, a 
cianamida hidrogenada é a principal substância utilizada para que ocorra a indução da brotação de diversas espécies de frutíferas de clima temperado (PETRI et al., 2016). Apesar de ser um tratamento eficaz para induzir a brotação, ela é prejudicial ao homem e ao meio ambiente, o que seria um entrave para a sua utilização (HAWERROTH et al., 2010a). Outra limitação em relação ao uso da cianamida hidrogenada é a restrição de seu uso em alguns países, podendo prejudicar as exportações brasileiras futuramente (UBER et al., 2017).

Ainda dentre os produtos disponíveis, está o $\operatorname{Erger}^{\circledR}$, um composto à base de nitrogênio que, simultaneamente com nitrato de cálcio, tem se mostrado promissor como indutor da brotação de gemas em macieira (PETRI et al., 2008; HAWERROTH et al., 2010b). De acordo com os mesmos autores, tem-se disponível uma alternativa: a mistura de Erger ${ }^{\circledR}$ com óleo mineral, mais viável economicamente para o produtor. Uber et al. (2017) concluíram em seus ensaios que Erger $^{\circledR}$ de $2 \%$ a $5 \%$, associado ao Nitrato de Cálcio 3\% e Assist (óleo mineral) 3,5\%+ Erger $^{\circledR} 1 \%$, mostrou-se eficiente na indução da brotação da macieira, comparando-se ao tratamento padrão de óleo mineral e Cianamida Hidrogenada (Dormex ${ }^{\circledR}$ ). E que a mistura Assist ${ }^{\circledR}$ $3,5 \%+$ Erger $^{\circledR} 1 \%$ tem menor custo que o tratamento padrão.

Embora existam muitas substâncias eficazes utilizadas na indução da brotação, poucas delas são aceitas e usadas comercialmente. O custo elevado e a alta toxicidade dos compostos são os principais fatores restritivos ao seu uso (PETRI et al., 2016). Apesar de existir muita informação a respeito de produtos utilizados para superar a dormência em algumas frutíferas de clima temperado, para a nogueira-pecã a pesquisa ainda é incipiente.

Keske et al. (2020) constataram que os tratamentos realizados com cianamida hidrogenada (nome comercial no Brasil: Dormex ${ }^{\circledR}$ ) são eficazes para adiantar a brotação de pecaneiras e obtiveram melhor efeito sobre os cultivares 'Melhorada', 'Imperial' e 'Importada' na concentração de $1 \%$, devido à uniformidade de distribuição das gemas nos estádios fenológicos. Os autores ainda apuraram que no cultivar Barton o uso de cianamida hidrogenada $1 \%$ e $2 \%$ mais $2 \%$ de óleo mineral e extrato oleo- so de alho, mais $2 \%$ de óleo mineral, foram significativamente mais eficientes na redução de gemas dormentes.

Existe ainda a possibilidade da utilização do thidiazuron (TDZ) para que seja feita a indução da brotação para a nogueira-pecã. Morales (2006) obteve resultados preliminares que indicam que o uso provocou um aumento na brotação apical e lateral, além de um maior desenvolvimento vegetativo do que reprodutivo.

Outra opção disponível é o Nitrato de potássio, comumente utilizado como fertilizante (fornece nitrogênio e potássio), que também atua na brotação, porém com efeito mais leve. Deve ser aplicado em plena dormência para promover principalmente as gemas floríferas na concentração de 5 a $7 \%$, permitindo também a combinação com óleo mineral, desde que em dose inferior a 5\% (INTAGRI, 2017).

Um potencial alternativo é a utilização de extrato de alho, pois tem em sua composição substâncias promotoras de crescimento como giberelinas e citocininas. Keske et al. (2020) realizaram ensaios com a nogueira-pecã e constataram que os tratamentos com extrato de alho tiveram um leve efeito na indução da brotação. Ainda de acordo com esses ensaios, os autores averiguaram que o extrato de alho industrial se mostrou mais eficaz do que o extrato de alho artesanal. Concluíram que para o cultivar Barton se obteve um melhor efeito com o tratamento contendo extrato de alho industrial devido à uniformidade, em relação aos tratamentos com cianamida hidrogenada.

\section{Considerações finais}

Os autores divergem quanto à necessidade de frio para a nogueira-pecã. Portanto, nesse sentido, mais estudos necessitam ser realizados. Além disso, a literatura é muito ampla, variando de 50 a mais de 550 horas de frio. Em relação aos produtos indutores, existem muitos disponíveis para serem usados como indutores de brotação, porém é necessário realizar mais ensaios para a cultura da nogueira-pecã, pois os dados ainda são insipientes e não estão elucidados.

\section{Referências}

BILHARVA, M.G., MARTINS, C.R., HAMANN,
J.J., FRONZA, D., DE MARCO, R., MALGARIM, M.B. Pecan: from Research to the Brazilian Reality. Journal of Experimental Agriculture International, v.23, n.6, p.1-16, 2018. DOI: http://dx.doi.org/10.9734/JEAl/2018/41899

CARDOSO, L. S.; BERGAMASCHI, H.; BOSCO, L. C.; DE PAULA, V. A.; NACHTIGAL, G. R. Unidades de frio para macieiras na região de Vacaria - RS, Brasil. Rev. Bras. Frutic., v.37, n.2, 289-295, 2015. DOI: https://doi. org/10.1590/0100-2945-136/14

CASALES, F. G.; VAN DER WATT, E.; COETZER, G. M. Propagação de Pecan (Carya illinoensis): Uma revisão. African Journal of Biotechnology, v.17, p.586-605, 2018. DOI: https://doi.org/10.5897/AJB2017.16183

COMENUEZ. Comité Mexicano del Sistema Producto Nuez. 2020. Disponível em: http:// www.comenuez.com/info-del-mercado. html. Acesso em: 20 Dezembro 2020.

FAUST, M.; EREZ, A.; ROWLAND, L.J.; WANG, S.Y.; NORMAN, H.A. Bud dormancy in perennial fruit trees: physiological basis for dormancy induction, maintenance, and release. HortScience, v. 32, n. 4, 623-629, p. 7. 1997. Disponível em: https://journals.ashs.org/ hortsci/view/journals/hortsci/32/4/articlep623.xml. Acesso em: 13 Junho 2020.

FRONZA, D.; HAMANN, J. J.; AMBOS, V.; ANESE, R. de O.; MEYER, E. A. Pecan cultivation: general aspects. Cienc. Rural v.48, n.2, 170-179, p.9. 2018. DOI: https://doi. org/10.1590/0103-8478cr20170179

GRAGEDA, J. G.; CORRAL, J. A. R.; ROMERO, G. E. G.; MORENO, J. H. N.; LAGARDA, J. V.; ÁlVAREZ, O. R.; LAGUNES, A. J. Efecto del cambio en la acumulación de horas de frío en la región nogalera de Hermosillo, Sonora. Revista Mexicana de Ciências Agrícolas. n.13, p.2487-2495, 2016. Disponível em: http://www.scielo.org.mx/scielo. php?script=sci_arttext\&pid=S20070934201 6000902487\&Ing=pt\&nrm=iso. Acesso em: 10 Novembro 2020.

GRAGEDA, J. G.; CASTILLO, A. A. F.; MORENO, J. H. N. Efecto de la temperatura en la acumulación de frío y la producción del nogal pecanero. Revista Pacana- Año 5, n.21, p.1013, 2019. Disponível em: http://comenuez. com/assets/ene-feb-digital-pacana-2019. pdf. Acesso em: 13 Jun. 2020.

GRAGEDA, J. G.; SANCHÉZ, N. C.; LAGUNES, A.J.; MORENO, H. N.; CASTILLO, A. A. F. Relación de la acumulación de frío y producción de nogal pecanero em Hermosillo, Sonora. Revista Pacana- Año 5, n. 28, p.32-34, 2020. Disponível em: http://www.comenuez. com/assets/sep-oct-digital-pacana-2020. pdf. Acesso em: 09 Jun. 2020. 
HAWERROTH, F.J.; HERTER, F.G.; PETRI, J.L.; LEITE, G.B.; PEREIRA, J.F.M. Dormência em frutíferas de clima temperado. (Documentos - 310), Embrapa Clima Temperado, Pelotas, p.1-57, 2010a. Disponível em: http:// ainfo.cnptia.embrapa.br/digital/bitstream/ item/44317/1/documento-310.pdf Acesso em: 11 Maio 2020.

HAWERROTH, F. J.; PETRI, J. L.; LEITE, G. B.; HERTER, F. G. Brotação de gemas em macieiras 'Imperial Gala' e 'Fuji Suprema' pelo uso de Erger $^{\circledast}$ e nitrato de cálcio. Rev. Bras. de Fruticultura, Jaboticabal, v.32, n.2, p.343350, 2010 b. Disponível em: https://www. scielo.br/pdf/rbf/v32n2/aop07810.pdf. Acesso em: 11 Maio 2020.

INTAGRI. Los Compensadores de Horas Frío en Frutales. Serie Frutales, n.31. Artículos Técnicos de INTAGRI. México. p.1-4, 2017. Disponível em: https://www.intagri.com/ articulos/frutales/los-compensadores-dehoras-frio-en-frutales. Acesso em: 11 Maio 2020.

KESKE, C.; VIEIRA, J. A.; FRANZÃO, M.; PADILHA, L H. P.; FOSTER, M. Efeito de cianamida hidrogenada e extrato de alho na quebra de dormência de cultivares de nogueira pecã no alto vale do Itajaí. Resultados Econômicos e de Sustentabilidade nos Sistemas nas Ciências Agrárias. Editora Atena. p.102-109, 2020. Disponível em: https://www.finersistemas.com/atenaeditora/index.php/admin/ api/artigoPDF/37374. Acesso em: 11 Novembro 2020.

KUDEN, A. B.; TUZCU, O.; BAYAZIT, S.; YILDIRIM, B.; IMRAK, B. Studies on the chilling requirements of pecan nut (Carya illionensis Koch) cultivars. African Journal of Agricultural Research. V.8, 3159-3165, p. 7. 2013. Disponível em: https://academicjournals.org/ article/article1380890377_Kuden\%20et\%20 al.pdf. Acesso em: 11 Maio 2020.

LANG, G. A.; EARLY, J. D.; MARTIN, G. C.; DARNELL, R. L. Endo-, para- and ecodormancy: physiological terminology and classification for dormancy research. Hortscience, v. 22, 371-377, p. 7. 1987. Disponível em: https://webcache.googleusercontent.com/search?q=cache:FDPLK FHKS8sJ:https://www.scienceopen.com/ document\%3Fvid\%3D72cb57c5-ade24529-b2ff-f7987d4b215e+\&cd=1\&hl=ptBR\&ct=clnk\&gl=br. Acesso em: 11 Novembro 2020 .

LEITE, G.B. A origem da heterogeneidade da brotação em regiões de inverno ameno. Agropecuária Catarinense, Florianópolis, v.33, n.1, 20-23, p. 4. 2020. Disponível em: https://www.researchgate.net/ publication/341372326_A_origem_da_he- terogeneidade_da_brotacao_em_regioes_de_inverno_ameno. Acesso em: 13 Jun. 2020.

LEMUS, G. El Cultivo del Pecano (Carya illinoensis). INIA Chile. 22p. Chile, 2004. Disponível em: https://bibliocapp.jimdo.com/ app/download/9332614252/Cultivo+Pecan. pdf?t=1394713693. Acesso em: 11 Out. 2020.

MARTINS, C. R.; CONTE, A.; FRONZA, D.; FILIPPINI ALBA, J. M.; HAMANN, J. J.; BILHARVA, M. G.; MALGARIM, M. B.; FARIAS, R. de M.; DE MARCO, R. ; REIS, T. Situação e perspectiva da nogueira-pecã no Brasil. Pelotas: Embrapa Clima Temperado, 1-33, p. 33. 2018 Disponível em: http://ainfo.cnptia.embrapa. br/digital/bitstream/item/187187/1/documento-462.pdf. Acesso em: 13 Julho 2020.

MELKE, A. The Physiology of Chilling Temperature Requirements for Dormancy Release and Bud-break in Temperate Fruit Trees Grown at MildWinter Tropical Climate. Journal of Plant Studies, v.4, n.2, p.110-156, p. 47. 2015. DOI: 10.5539 / jps.v4n2p110

MCWILLIAMS, J. The pecan: A history of America's native nut. Austin: Hardcover, p.1178, 2013.

MORALES, M. del C. M. Efecto del thidiazuron en el desarrollo y producción del nogal pecanero. Agrofaz, v.6, n. 2, p.171-178, 2006. Disponível em : https://dialnet.unirioja.es/servlet/articulo?codigo $=2303546$. Acesso em: 19 Ag. 2020.

OJEDA-BARRIOS, D. L. et al. Evolución de los sistemas de producción de nuez em México. Tecnociencia, Chihuahua, v.3, n.3, p.115120, 2009. Disponível em: http://tecnociencia.uach.mx/numeros/v3n3/data/Evolucion_de_los_sistemas_de_produccion_de nuez_en_Mexico. Acesso em: 11 Maio 2020.

PETRI, J.L.; PALLADINI, L.A.; POLA, A.C. Dormência e indução a brotação em macieira. In: EPAGRI. A cultura da macieira. Florianópolis, p.261-297, 2006.

PETRI, J.L.; LEITE, G.B.; PUTTI, G.L. Apple tree bud-break promoters in mild winter conditions. Acta Horticulturae, Seoul, v.774, p.291- 296, 2008. DOI: 10.17660 / ActaHortic.2008.774.39

PETRI, J.L.; HAWERROTH, F.J.; LEITE, G.B.; SEZERINO, A.A.; COUTO, M.; Reguladores de crescimento para frutíferas de clima temperado.1a Edição. Florianópolis: Epagri, 1-145, p.145. 2016. Disponível em: https:// www.alice.cnptia.embrapa.br/bitstream/ doc/1067694/1/LIVROReguladoresdecrescimentoparafrutiferasdeclimatemperadocorrigidoOKneu.pdf. Acesso em: 11 Maio 2020.
POLETTO, T.; MUNIZ, M. F. B.; POLETTO, I.; STEFENON, V. M.; MACIEL, C. G.; RABUSQUE, J. E. Superação de dormência e qualidade de mudas de nogueira-pecã em viveiro. Cienc. Rural, v.46, n.11. p.1980-1985, 2016. DOI: https://doi.org/10.1590/01038478 cr20150835.

RASEIRA, A. A cultura da nogueira-pecã ( $C a-$ rya illinoenensis). Pelotas: Embrapa Clima Temperado, p.3. 1990. (Embrapa Clima Temperado. Comunicado Técnico, 63). Disponível em: http://www.infoteca.cnptia.embrapa.br/infoteca/handle/doc/743219. Acesso em: 23 Novembro 2020.

RICHARDSON, E.A.; SEELEY, S.D.; WALKER, D.R. A model for estimating the completion of rest for 'Redhaven' and 'Elberta' peach trees. HortScience, Alexandria, v.9, n.4, 331332, 1974.

ROVANI, F. F. M.; WOLLMANN, C. A. Análise sazonal e anual dos requisitos climáticos do cultivo da nogueira pecã (Carya illinoinensis) no Rio Grande do Sul. Geousp - Espaço e Tempo (Online), v.22, n.1, p.191-209, 2018. https://doi.org/10.11606/issn.2179-0892. geousp.2018.122043

RUIZ, D.; CAMPOY, J.A.; EGEA, J. Chilling and heat requirements of apricot cultivars for flowering. Environmental and Experimental Botany, v.61, p. 254-263, 2007. https://doi. org/10.1016/j.envexpbot.2007.06.008

SANTOS, D.F.; LEITE, R.R.M.; MARTINS, F.B. Avaliação de métodos de estimativa de número de horas frio para o Sul e sudoeste do Paraná. Revista Brasileira de Climatologia, v.21. 401-416, p.16. 2017. DOI: http:// dx.doi.org/10.5380/abclima.v21i0.52382

SHALTOUT, A.D.; UNRATH, C.R. Rest completion prediction model for 'Starkrimson Delicious' apples. Journal of the American Society for Horticultural Science, Alexandria, v.108, n.6, 957-961, 1983.

UBER, S. C; PETRI, J. L.; FAGUNDES, E.; COUTO, M.; FRANCESCATTO, P.; ESPERANÇA, C. F. Eficiência do Erger $^{\circledR}$ como indutor de brotação em alternativa a cianamida hidrogenada. Revista da Jornada da Pós-Graduação e Pesquisa. Urcamp, p.16. 2017. Disponível em http://revista.urcamp.tche.br/index. php/rcjpgp/article/view/823/519. Acesso em: 11 Maio 2020.

WELLS, L. Pecan: America's native nut tree. Tuscaloosa: The University of Alabama Press, 264p. 2017a.

WELLS, L. Southeastern Pecans Growers' Handbook. University of Georgia, 236p. 2017b. 